\title{
The association between nutritive, non- nutritive sucking habits and primary dental occlusion
}

\author{
Hiu Tung Bonnie Ling ${ }^{1 \dagger}$, Fung Hou Kumoi Mineaki Howard Sum ${ }^{1 \dagger}$, Linkun Zhang ${ }^{2}$, Cindy Po Wan Yeung ${ }^{3}$, \\ Kar Yan Li ${ }^{3}$, Hai Ming Wong ${ }^{1}$ and Yanqi Yang ${ }^{1 *}$
}

\begin{abstract}
Background: The development of primary dentition can be affected by oral sucking habits. Therefore, this study aims to investigate the association of nutritive and non-nutritive sucking habits with primary dentition development.

Methods: One thousand one hundred and fourteen children aged 2 to 5 years old in Hong Kong were recruited in a cross-sectional study. Information on their nutritive (e.g. breastfeeding and bottle feeding) and non-nutritive sucking habits (e.g. pacifier use and thumb/digit sucking) was collected via questionnaires. The children's primary occlusions were examined in three dimensions.

Results: Children who were breastfed for more than 6 months had a lower proportion of daily pacifier use $(p<0.05)$. Children who used pacifiers daily had a higher proportion of thumb/digit sucking $(p<0.05)$. Children who used pacifiers daily for more than one year had higher chances of developing an anterior open bite $(p<0.05)$ and a reduced overbite $(p<0.05)$. Those exhibiting daily thumb/digit sucking for more than one year had higher chances of developing Class II incisor and Class II canine relationships, an increased overjet and anterior open bite $(p<0.05)$.

Conclusion: Pure breastfeeding for more than 6 months is inversely associated with daily pacifier use and daily pacifier use is positively associated with daily thumb/digit sucking. Children with more than one year of daily pacifier use and thumb/digit sucking have higher chances of developing abnormal dental relationships in the sagittal (i.e. Class II incisor and Class II canine relationships and increased overjet) and vertical (i.e. anterior open bite) dimensions, respectively.
\end{abstract}

Keywords: Nutritive sucking habit, Non-nutritive sucking habits, Primary dental occlusion

\section{Background}

Primary dentition is the foundation for the development of permanent dentition, in terms of determining space and occlusion for future developing teeth. Malocclusion is a developmental disorder of the maxillofacial system that results from genetic and environmental factors and affects the jaw, tongue and facial soft tissues [1]. As sucking habits are variable environmental factors, knowledge of how such behaviour contributes to or prevents malocclusion can help determine better options for

\footnotetext{
* Correspondence: yangyanq@hku.hk

${ }^{+}$Hiu Tung Bonnie Ling and Fung Hou Kumoi Mineaki Howard Sum contributed equally to this work.

${ }^{1}$ Department of Paediatric Dentistry and Orthodontics, Faculty of Dentistry, Prince Philip Dental Hospital, The University of Hong Kong, 2/F, 34 Hospital Road, Sai Ying Pun, Hong Kong SAR, China

Full list of author information is available at the end of the article
}

children's oral health care. Oral sucking habits, such as breastfeeding and bottle sucking, can be categorised as nutritive habits, which are for feeding children, and non-nutritive habits, such as thumb sucking, finger sucking or pacifier use, which are often used to calm and comfort infants [2]. The calming effects have also been used to provide pain relief during minor procedures such as immunization [3]. Apart from the calming effects and providing a sense of security, pacifier use has been found to be associated with protection of sudden infant death syndrome [3-5].

Breastfeeding is a nutritive sucking habit that has been found to have general, immunological, nutritional and oral benefits for the child [6]. The World Health Organization (WHO) recommends exclusive breastfeeding for the first 6 months of life, with some breastfeeding

(c) The Author(s). 2018 Open Access This article is distributed under the terms of the Creative Commons Attribution 4.0 International License (http://creativecommons.org/licenses/by/4.0/), which permits unrestricted use, distribution, and reproduction in any medium, provided you give appropriate credit to the original author(s) and the source, provide a link to the Creative Commons license, and indicate if changes were made. The Creative Commons Public Domain Dedication waiver (http://creativecommons.org/publicdomain/zero/1.0/) applies to the data made available in this article, unless otherwise stated. 
up to 2 years of age [1,7]. Our recent study showed that pure breastfeeding is associated with reduced chances of developing abnormal primary dentition, such as lower chances of having a Class II incisal relationship and increased overjet. We also found that children with pure breastfeeding for more than 6 months have wider intercanine and intermolar widths [8].

Sucking is a natural instinct and is a baby's earliest coordinated muscular activity. The action of breastfeeding uses intensive muscular activity and benefits oral motor development $[9,10]$. This repetitive action increases muscle tone and promotes correct development, thus ensuring correct oral function [11]. Other oral habits, such as pacifier use or bottle feeding, produce different functional stimuli [12]. It has been found that those who use pacifiers for more than 6 months and those who bottle feed for over 1 year score lower on masticatory function assessments [12].

When an infant does not breastfeed sufficiently, they may develop other types of sucking habits [13]. Some infants adopt non-nutritive sucking habits to cope with frustration, decreased sense of security or an urge for contact [14]. Certain studies have investigated the association between breastfeeding and non-nutritive sucking habits (i.e. pacifier use and thumb sucking) [2, 15-17]. These studies have reported that breastfeeding is associated with lower chances of pacifier use. However, few have focused on the duration or the frequency of these habits $[2,15,17]$. This is rather important from a dental point of view, because the frequency and magnitude of force are crucial for occlusion development, which may lead to malocclusion in the primary dentition. No study has looked into whether or how non-nutritive sucking habits are interrelated.

Knowing the beneficial oral effects of breastfeeding versus bottle feeding [8], it is also worthwhile to know the effects of non-nutritive oral habits. In contrast to calming and comforting infants, pacifier use is reported to have some unfavourable oral effects. If pacifiers are given to infants when they are learning to suck from their mothers' breasts in the early postpartum period, the use of pacifiers may interfere with proper sucking and cause nipple confusion [18]. Studies have found pacifier use to be associated with an increased prevalence of oral candidiasis, a type of fungal infection [19-22]. Several studies also show that non-nutritive sucking habits are associated with the development of malocclusion in the primary dentition [1, 12, 18]. Nevertheless, the majority of the existing studies do not address the effects of the duration or frequency of non-nutritive sucking habits. However, it is important for dentists and parents to know the frequency and duration of the force required to affect occlusion.
Therefore, the present study aims to (1) determine the associations between nutritive and non-nutritive sucking habits; (2) assess the interrelation between different non-nutritive sucking habits, pacifier use and thumb/ digit sucking; and (3) investigate the relationships between various non-nutritive sucking habits and occlusion in the primary dentition. To be representative of having a habit, the frequency and duration of the non-nutritive sucking habits will be emphasised when performing the analyses.

\section{Methods \\ Samples}

A total of 10 kindergartens from different districts of Hong Kong participated in our study. This cross-sectional study was carried out with ethics board approval (HKU/ HA HKW IRB: UW12-334) and parental consent forms were collected before the examinations. One thousand one hundred and fourteen children aged 2 to 5 years old participated in the survey. Among the one thousand one hundred and fourteen children, only eight hundred and fifty-one children took part in the oral examination and also completed all the questions in the questionnaires.

Fewer participants were recruited for the oral examinations compared to the surveys, as some did not return consent forms to undergo oral examination, refused examination or were uncooperative upon examination. To maintain the integrity of the study results, participants with severe skeletal discrepancy, with cleft lip or palate, or who were non-Asian were excluded. Only children with primary dentition were included in this study.

In a previous similar study, the probability of the event (Class II canine relationship and increased overjet) is around $20 \%$ for those without pacifier/digit-sucking habit and the allocation ratio of having pacifier/digit-sucking habit: no habit is about 1.6:1 [23], it was estimated that a sample of 476 individuals would have $90 \%$ chance of detecting an odds ratio of 2 with the two-sided significance level setting at 0.05 .

Given this sample size determinations and assuming $20 \%$ possible non-responses and loses, the final study population had to be at least 595 . As the study recruited 851 subjects who participated in both questionnaires and oral examinations, the sample size was sufficient.

\section{Data collection}

The questionnaires were completed by the children's parents or guardians and collected information regarding the frequencies and durations of the children's nutritive and non-nutritive sucking habits. After collecting the questionnaires, those who had left certain sections incomplete were contacted by telephone.

One examiner who had more than 5 years of orthodontic training performed all of the oral examinations 
throughout the study. The examiner performed calibration with another orthodontist before the study. The examination was carried out in the kindergartens with the children in the lying-down position. The equipment used included oral mirrors, probes and rulers. The children's dental arch relationships were examined in three dimensions (sagittal, vertical and transverse) as listed in Table 1. Duplicated data were collected for $6.23 \%$ of the subjects to assess the intra-examiner reliability.

\section{Statistical analysis}

The associations between different oral habits and their relationships with occlusion were analysed by multinomial logistic regression, logistic regression and multi-way analysis of variance (ANOVA) using the Statistical Package for the Social Sciences (SPSS) (IBM) version 20.0.
Multinomial logistic regressions were used to investigate the associations between the categorical variables, such as the primary incisal, canine and molar relationships with different sucking habits.

Multivariable logistic regression models were used to investigate the associations between the binary outcome variables, such as the associations between the frequencies of non-nutritive sucking habits and breastfeeding durations, between the different non-nutritive sucking habits and between different non-nutritive sucking habits and overjet, anterior crossbite, open bite, overbite and posterior crossbite.

Multi-way ANOVA using the Bonferroni correction of pairwise comparisons was used to compare the mean intercanine and intermolar widths in children exhibiting different non-nutritive sucking habits.

The significance level was set at $p<0.05$.

Table 1 Oral examination criteria of the children's three-dimensional dental arch relationships

Sagittal
Incisal relationship- Classified into three
categories:
Class I, the lower incisor edges occlude with or lie
immediately below cingulum plateau of the
upper central incisors; Class II, the lower incisor
edges lie posterior to the cingulum plateau of the
upper incisors; Class III, the lower incisor edges lie
anterior to the cingulum plateau of the upper
incisors. The overjet is reduced or reversed [44].
Canine relationship- Classified into
three categories:
Class I, the tip of the maxillary primary canine
tooth is in the same vertical plane as the distal
surface of the mandibular primary canine; Class II,
the tip of the maxillary primary canine tooth is
mesial to the distal surface of the mandibular
primary canine; Class III, the tip of the maxillary
primary canine is distal to the distal surface of
the mandibular primary canine [11].

Molar relationship - Classified into three categories:

Flush terminal, where the distal surfaces of the upper and lower second primary molars are in the same vertical plane in a centric occlusion; Distal step, where the distal surfaces of the lower primary second molar are in a posterior relationship to the distal surface of the upper second molars in centric occlusion; Mesial step, the distal surfaces of the lower primary second molar are in an anterior relationship to the distal surface of the upper second molars in centric occlusion [11].

Anterior crossbite - It was recorded when one or more of the maxillary incisors occluded lingual to the mandibular incisors [45].

Overjet- Measured from the palatal surface of the mesial corner of the most protruded fully erupted maxillary incisor to the labial surface of the corresponding mandibular incisor [11]. The degree of overjet was recorded in millimeters. In this study, an overjet of greater than $3.5 \mathrm{~mm}$ was considered an increased overjet.

\begin{tabular}{ll} 
Vertical & Transverse \\
\hline Overbite- Coverage of the mandibular & Intermolar width- Distance between \\
incisor by the most protruded fully erupted & mesiobuccal cusp tips of the maxillary \\
maxillary incisor and recorded as $<1 / 2$ or $\geq$ & second primary molars [40].
\end{tabular}
$1 / 2[11]$.

Anterior openbite- When there are no vertical contacts between upper and lower incisal edges [9].
Intercanine width- Distance from cusp tip to cusp tip of the maxillary primary canines [40].
Posterior crossbite- Recorded when one or more of the maxillary primary canines or molars occluded lingual to the buccal cusps of the opposing mandibular teeth [11]. 


\section{Results}

\section{Sample characteristics and measurement error}

The survey included 1114 children aged 2 to 5 years old. The boy $(n=609,54.7 \%)$ to girl $(n=500,44.9 \%)$ ratio was 1.22. Five children's parents did not answer the question on the children's gender.

Regarding the intra-examiner reliability, the Cohen's kappa coefficients ranged from 0.70 to 1.00 and the Interclass Correlation Coefficient (ICC) ranged from 0.89 to 0.98 , indicating that the categorical data were in substantial to perfect agreement and the continuous data had excellent reproducibility [24, 25].

\section{Correlations between nutritive and non-nutritive sucking habits}

Among the 1114 children who had participated in the survey, 80 participants did not provide complete answers to questions on duration of breastfeeding, frequency of pacifier use or frequency of thumb/digit sucking. Therefore, only 1034 children were included in the analysis (Tables 2 and 3).

Significant association was found between the duration of breastfeeding and the frequency of pacifier use ( $p=$ 0.000 ). The children who had experienced pure breastfeeding for more than 6 months had a significantly lower chance of daily pacifier use (multinomial logistic regression: $p=0.000$; adjusted odds ratio $[\mathrm{OR}]=0.412,95 \%$ confidence interval [CI] 0.259-0.655). However, no association between the duration of pure breastfeeding and the development of habitual thumb/digit sucking was found (multinomial logistic regression $p>0.05$ ). The associations between the duration of breastfeeding and the frequency of pacifier and thumb/digit sucking are presented in Table 2.

\section{Correlations between non-nutritive sucking habits}

Children who used pacifiers daily had significantly higher chances of having daily thumb/digit sucking habits (logistic regression: $p=0.023$; adjusted $\mathrm{OR}=2.136,95 \% \mathrm{CI}$ 1.112-4.103) (Table 3).

\section{Associations between non-nutritive sucking habits and primary dental relationships}

Among the 1114 children who had participated in the survey, 851 children took part in the oral examination and also completed all the questions in the questionnaires. Hence, the following tables (Tables 4, 5, 6 and 7) are analysis based on the 851 children.

\section{Sagittal dimension}

In terms of frequency, the children with daily thumb/ digit sucking habits had significantly higher chances of developing Class II incisor relationships (multinomial logistic regression: $p=0.008$; adjusted $\mathrm{OR}=2.237,95 \% \mathrm{CI}$ 1.290-3.877), Class II canine relationships (multinomial logistic regression: $p=0.036$; adjusted $\mathrm{OR}=2.595,95 \%$ CI 1.117-6.025) and overjets $>3.5 \mathrm{~mm}$ (logistic regression: $p=0.000$; adjusted $\mathrm{OR}=2.879$, 95\% CI $1.624-$ 5.101) than those without daily thumb/digit sucking habits (Table 4). However, the frequency of pacifier use was not associated with primary incisor, primary canine or primary molar relationships (multinomial logistic regression: $p>0.05$ ) (Table 4).

Regarding duration, the children who exhibited daily thumb/digit sucking for more than a year had significantly higher chances of developing Class II incisor relationships (multinomial logistic regression: $p=0.001$; adjusted OR $=2.930$, 95\% CI 1.628-5.274), Class II canine relationships (multinomial logistic regression: $p=$ 0.005 ; adjusted $\mathrm{OR}=3.483$, 95\% CI $1.312-9.245)$ and overjets > $3.5 \mathrm{~mm}$ (logistic regression: $p=0.000$; adjusted OR 3.603 , 95\% CI 1.987-6.533) than those without daily thumb/digit sucking habits (Table 5). Similar to the analysis of frequency, the duration of daily pacifier use was found to have no association with primary incisor, primary canine or primary molar relationships (multinomial logistic regression: $p>0.05$ ) (Table 5).

\section{Vertical dimension}

In terms of frequency, the children who used pacifiers daily had significantly higher chances of developing an anterior open bite (logistic regression: $p=0.000$; adjusted $\mathrm{OR}=10.149,95 \%$ CI $3.798-27.122)$ and significantly

Table 2 Association between the duration of breastfeeding and frequency of non-nutritive sucking habits $(n=1034)$

\begin{tabular}{|c|c|c|c|c|c|c|c|c|}
\hline & \multirow[b]{2}{*}{$n$} & \multirow[b]{2}{*}{$\%$} & \multicolumn{3}{|c|}{ Daily pacifier vs non daily pacifier } & \multicolumn{3}{|c|}{ Daily thumb/digit sucking vs non daily thumb/digit sucking } \\
\hline & & & OR & $95 \% \mathrm{Cl}$ & $p$-value & OR & $95 \%$ Cl & $p$-value \\
\hline \multicolumn{3}{|c|}{ Duration of breastfeeding } & & & $0.000^{*}$ & & & 0.143 \\
\hline$>6$ months & 246 & 23.8 & 0.412 & $0.259-0.655$ & $0.000^{*}$ & 0.599 & $0.318-1.128$ & 0.112 \\
\hline $0-6$ months & 471 & 45.6 & 0.840 & $0.598-1.180$ & 0.134 & 1.042 & $0.645-1.683$ & 0.867 \\
\hline Never & 317 & 30.7 & 1 & - & - & 1 & - & - \\
\hline
\end{tabular}

$O R$ odds ratio, $\mathrm{Cl}$ confidence interval

a Adjusted for background information (age and gender)

* $p<0.05$

Boldface data are variables with $p<0.05$ or OR $(95 \% \mathrm{Cl})<1$ 
Table 3 Association between the frequency of pacifier use and frequency of thumb/digit sucking $(n=1034)$

\begin{tabular}{|c|c|c|c|c|c|}
\hline \multirow{2}{*}{$\begin{array}{l}\text { Frequency of } \\
\text { pacifier use }\end{array}$} & \multirow[b]{2}{*}{$\mathrm{n}$} & \multirow[b]{2}{*}{$\%$} & \multicolumn{3}{|c|}{ Daily thumb/digit sucking vs non daily thumb/digit sucking } \\
\hline & & & OR & $95 \% \mathrm{Cl}$ & $p$ value \\
\hline Daily pacifier & 212 & 20.5 & 2.136 & $1.112-4.103$ & $0.023^{*}$ \\
\hline Non daily pacifier & 822 & 79.5 & 1 & - & - \\
\hline
\end{tabular}

OR odds ratio, $\mathrm{Cl}$ confidence interval

${ }^{a}$ Adjusted for background information (age and gender) and duration of pure breastfeeding

${ }^{*} p<0.05$

Boldface data are variables with $p<0.05$ or OR $(95 \% \mathrm{Cl})<1$

lower chances of developing an overbite greater than half of the lower incisor (logistic regression: $p=0.004$; adjusted OR $=0.555,95 \%$ CI $0.373-0.825$ ) than those who did not use pacifiers daily. In addition, children with daily thumb/digit sucking habits had significantly higher chances of developing an anterior open bite (logistic regression: $p=0.046$; adjusted $\mathrm{OR}=3.440,95 \% \mathrm{CI}$ 1.020-11.597) (Table 6). The frequency of thumb/digit sucking was not associated with the extent of the anterior overbite formed (logistic regression: $p>0.05$ ) (Table 6).

The results of the duration analyses were very similar to those of frequency analyses. The children who experienced daily pacifier use for more than 1 year had significantly higher chances of developing an anterior open bite (logistic regression: $p=0.000$; adjusted $\mathrm{OR}=15.171$, 95\% CI 5.298-43.446) and significantly lower chances of developing an overbite greater than half of the lower incisor (logistic regression: $p=0.045$; adjusted $\mathrm{OR}=0.577$, 95\% CI 0.340-0.890) than those who never had the habit of daily pacifier use (Table 7). In addition, children who displayed daily thumb/digit sucking for more than 1 year had significantly higher chances of developing an anterior open bite (logistic regression: $p=0.006$; adjusted OR $=6.383,95 \%$ CI $1.689-24.120)$ than those who had never displayed daily thumb/digit sucking habits (Table 7).

\section{Transverse dimension}

The frequency and duration of pacifier use and thumb/ digit sucking were neither associated with the development of posterior crossbite (logistic regression: $p>0.05$ ) nor the intercanine (ANOVA: $p>0.05$ )/intermolar widths (ANOVA: $p>0.05$ ).

\section{Discussion}

First, this study assessed the association between nutritive and non-nutritive sucking habits. It was found that children who were breastfed for more than 6 months had significantly less daily pacifier use. No relationship was found between breastfeeding and thumb/digit sucking. The relationship between breastfeeding and pacifier use is consistent with previous studies [17, 26]. Breastfeeding has been found to use more musculature and facilitates the development of the correct orofacial muscles [11, 12, 27]. With unrestricted breastfeeding infants experience improved safety and satisfaction, and thus no other sucking actions are needed, which leads to less pacifier use [11]. One study found increased digit sucking when breastfeeding lasted less than 6 months [15]. However, another study focusing on the frequency of thumb sucking found no relationship to breastfeeding [18], which is similar to our results. The variability between studies may be due to whether the frequency of thumb sucking was taken into account when the data were analysed.

Second, this study assessed the interrelation between different non-nutritive sucking habits. It was found that more daily pacifier use increased the chances for more thumb/digit sucking habits. Not many studies have focused on the relationship between pacifier use and thumb sucking, apart from a study done in 1977 that found an inverse association between the two habits [28]. A possible explanation as to why pacifier use increased thumb/digit sucking in our study is that adaptation to one habit may increase the urge for and addiction to the sucking sensation. In addition, when infants are not sufficiently satisfied by thumb/digit sucking, they may develop other habits to help them to fulfil their needs.

Third, this study investigated the effects of non-nutritive sucking habits on primary dental relationships. In the sagittal dimension, the results of this study agree with previous studies in that thumb sucking is associated with Class II incisor relationships, Class II canine relationships and also increased overjet [29-35]. The higher incidence of increased overjet may be due to proclination of the maxillary incisors and forward displacement of the maxillary base as a result of the pressure of the thumb [36-38]. The overjet may also be worsened by retroclination of the lower incisors due to the lever action of the thumb [39]. The increase in Class II canine relationships may be due to the forward displacement of the anterior maxillary base $[35,39]$.

Some existing studies have found that pacifier use is associated with increased overjet [11, 40, 41]. Nevertheless, this study did not find any association between pacifier use and the development of primary dentition in the sagittal dimension. The difference may be because the previous studies have not assessed the frequency or duration of pacifier use. Furthermore, most studies have 


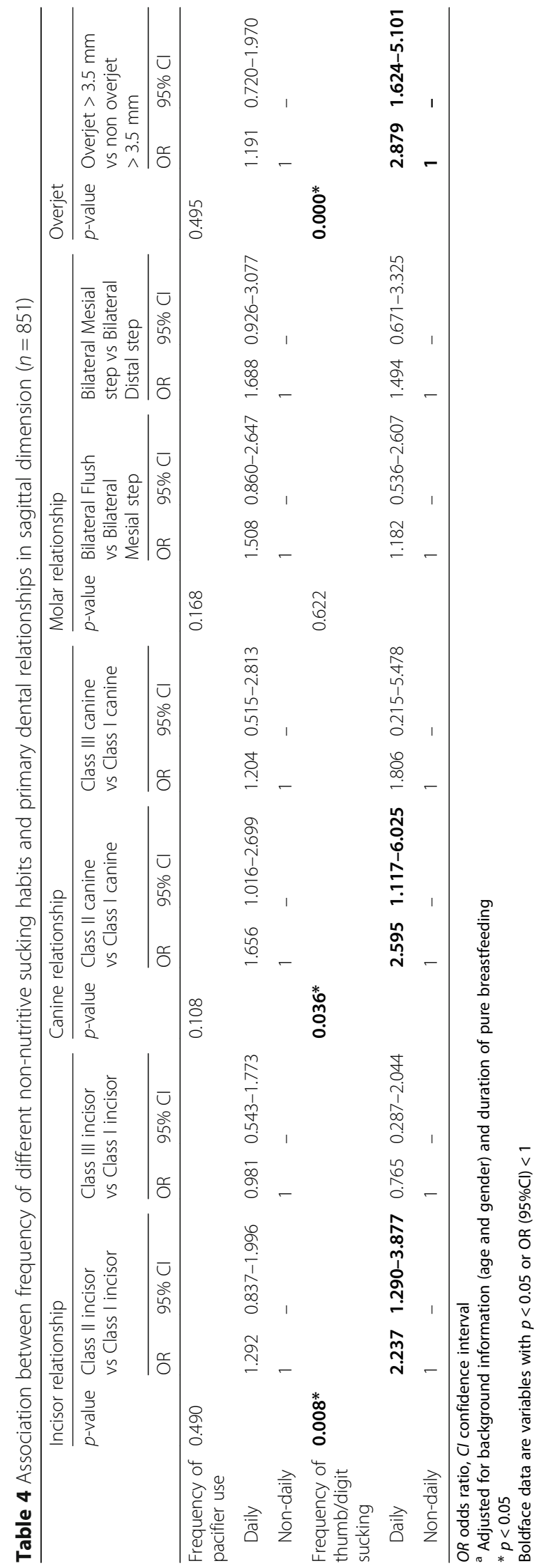




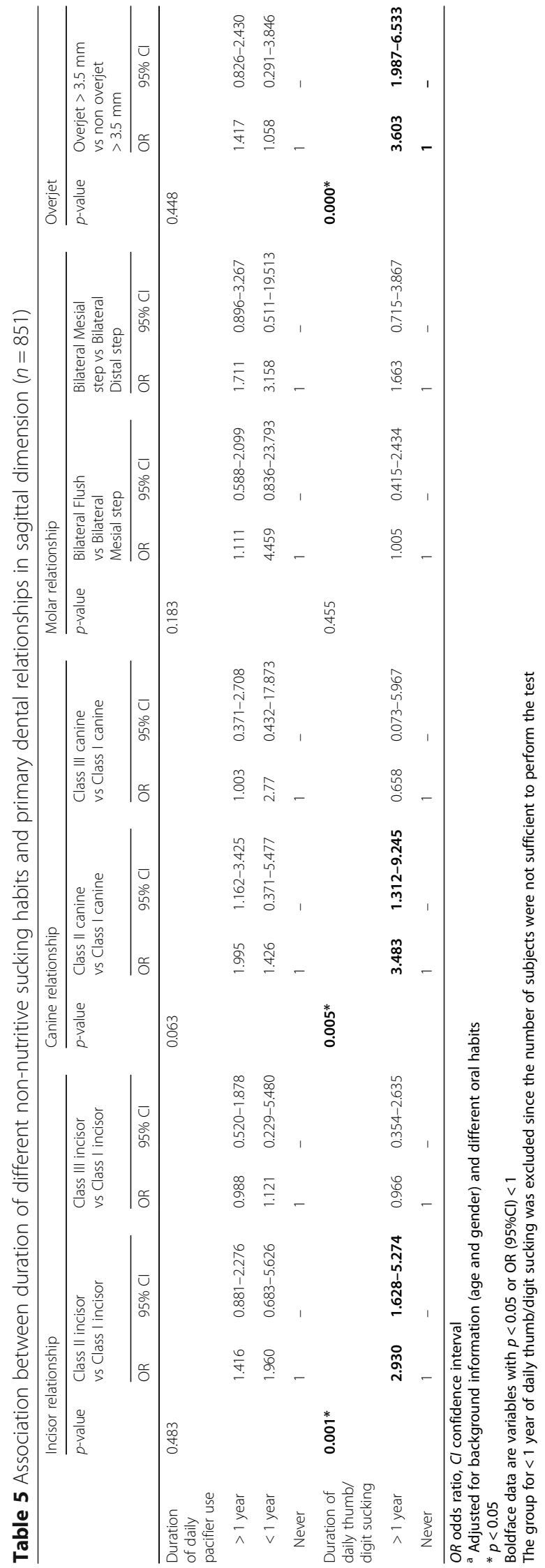


Table 6 Association between frequency of different non-nutritive sucking habits and primary dental relationships in vertical dimension $(n=851)$

\begin{tabular}{|c|c|c|c|c|c|c|}
\hline & \multicolumn{3}{|c|}{ Anterior openbite } & \multicolumn{3}{|c|}{ Anterior overbite } \\
\hline & \multirow[t]{2}{*}{$p$-value } & \multicolumn{2}{|c|}{ Anterior openbite vs non-anterior openbite } & \multirow[t]{2}{*}{$p$-value } & \multicolumn{2}{|c|}{ Overbite $\geq 1 / 2$ vs overbite $<1 / 2$} \\
\hline & & OR & $95 \% \mathrm{Cl}$ & & $\overline{\mathrm{OR}}$ & $95 \% \mathrm{Cl}$ \\
\hline Frequency of pacifier use & $0.000^{*}$ & & & $0.004^{*}$ & & \\
\hline Daily & & 10.149 & $3.798-27.122$ & & 0.555 & $0.373-0.825$ \\
\hline Non-daily & & 1 & - & & 1 & - \\
\hline Frequency of thumb/digit sucking & $0.046^{*}$ & & & 0.128 & & \\
\hline Daily & & 3.440 & $1.020-11.597$ & & 0.653 & $0.377-1.130$ \\
\hline Non-daily & & 1 & - & & 1 & - \\
\hline
\end{tabular}

$O R$ odds ratio, $\mathrm{Cl}$ confidence interval

${ }^{a}$ Adjusted for background information (age and gender) and duration of pure breastfeeding

* $p<0.05$

Boldface data are variables with $p<0.05$ or OR $(95 \% \mathrm{Cl})<1$

not considered thumb/digit sucking as a confounding factor. In addition, there are different types of pacifiers on the market; different pacifier designs may affect the results.

In the vertical dimension, the results of this study agree with those of existing studies in that thumb/digit sucking and pacifier use are associated with increased open bite [42]. Pressure from the thumb or pacifier hinders the downward growth of the maxillary base and delays the anterior teeth from erupting while the posterior teeth continue to erupt. This results in overeruption of the posterior teeth and the formation of an anterior open bite [11, 33, 35, 36, 43].

Multiple studies have found that non-nutritive sucking habits are associated with smaller maxillary intercanine and intermolar widths and increased posterior crossbite $[29,41]$. Nevertheless, this study found no association between non-nutritive sucking habits in the transverse dimension of the primary dentition. These inconsistent findings can be explained by the fact that most of the studies have not accounted for confounding factors, such as age, gender and other non-nutritive sucking habits, in their statistical analyses. Furthermore, many studies have not investigated the frequency or duration of the habits.

The results of this study show that pure breastfeeding for more than 6 months lowered pacifier use, which was associated with less thumb/digit sucking. Together, less pacifier use and less thumb/digit sucking benefited primary dental relationship development in the sagittal and vertical dimensions. These results raise three important points. First, pure breastfeeding for more than 6 months prevents non-nutritive sucking habits. Second, there is a correlation between variable non-nutritive sucking habits. Thus, preventing or breaking a non-nutritive sucking habit may prevent or break others. Third, preventing or breaking non-nutritive sucking habits is important for the development of primary dentition.

This study did have its limitations. The random selection of subjects was difficult, as we needed approval

Table 7 Association between duration of different non-nutritive sucking habits and primary dental relationships in vertical dimension $(n=851)$

\begin{tabular}{|c|c|c|c|c|c|c|}
\hline & \multicolumn{3}{|c|}{ Anterior openbite } & \multicolumn{3}{|c|}{ Anterior overbite } \\
\hline & \multirow[t]{2}{*}{$p$-value } & \multicolumn{2}{|c|}{ Anterior openbite vs non-anterior openbite } & \multirow[t]{2}{*}{$p$-value } & \multicolumn{2}{|c|}{ Overbite $\geq 1 / 2$ vs overbite $<1 / 2$} \\
\hline & & OR & $95 \% \mathrm{Cl}$ & & OR & $95 \% \mathrm{Cl}$ \\
\hline Duration of daily pacifier use & $0.000^{*}$ & & & $0.045^{*}$ & & \\
\hline$>1$ year & & 15.171 & $5.298-43.446$ & & 0.577 & $0.374-0.890$ \\
\hline$<1$ year & & 0.000 & $0.000-0.000$ & & 0.881 & $0.302-2.570$ \\
\hline Never & & 1 & - & & 1 & - \\
\hline Duration of daily thumb/digit sucking & $0.006^{*}$ & & & 0.122 & & \\
\hline$>1$ year & & 6.383 & $1.689-24.120$ & & 0.631 & $0.352-1.131$ \\
\hline Never & & 1 & - & & 1 & - \\
\hline
\end{tabular}

$O R$ odds ratio, $C l$ confidence interval

${ }^{a}$ Adjusted for background information (age and gender) and duration of pure breastfeeding

* $p<0.05$

Boldface data are variables with $p<0.05$ or OR $(95 \% \mathrm{Cl})<1$

The group for $<1$ year of daily thumb/digit sucking was excluded since the number of subjects were not sufficient to perform the test 
from their schools to take part in the study. Effort was made to spread out the samples across the main territories of Hong Kong. As this is a retrospective study, recall bias is possible. As parents are unable to monitor their children for $24 \mathrm{~h}$ each day, there may be an underestimation of thumb/digit sucking habits. Furthermore, the survey questions may have had overlapping response options (e.g. ' $0-6$ months' and ' $6-12$ months'). During the oral examinations, the children were all in the lyingdown position to prevent them from moving around; however, it may have been more accurate if they were sitting down instead. Finally, it was difficult to assess whether the child had mild skeletal discrepancy without the use of radiographs.

\section{Conclusion}

Breastfeeding for more than 6 months is negatively associated with pacifier use. Pacifier use is positively associated with thumb/digit sucking. Pacifier use and thumb/ digit sucking are associated with higher chances of malocclusion in the sagittal (i.e. Class II incisal relationships, Class II canine relationships and increased overjet) and vertical (i.e. anterior open bite) dimensions of the primary dentition.

\section{Abbreviations}

ANOVA: Analysis of variance; ICC: Interclass Correlation Coefficient; OR: Odds ratio; SPSS: Statistical Package for the Social Sciences; WHO: World Health Organization

\section{Acknowledgements}

We thank the ten nursery schools who participated in the study and extend special thanks to Hong Kong Society for the Protection of Children. Dr. Karen Yuet Wa Hung's support to this project is much appreciated. We also thank the helpers' contribution during the outreach survey.

\section{Funding}

The project was supported by the Seed Funding for Basic Research, the University of Hong Kong (201611159297). The funding body played no role in the design of the study and collection, analysis, and interpretation of data and in writing the manuscript.

\section{Availability of data and materials}

All data generated or analysed during this study are included in this published article and its supplementary information files.

\section{Authors' contributions}

All authors read and approved the final manuscript. HTBL: Questionnaire design, write up of the manuscript. FHKMHS: Examination form design, data analysis, write up of the manuscript. LZ: Examination of participants, manuscript write up especially on section of oral examinations. CPWY: Examination arrangement, data input, manuscript write up especially on section of data collection. KYL: Data analysis, manuscript write up especially on section of statistical analysis. HMW: Questionnaire design, manuscript write up especially on section of analysis of questionnaires. YY: Study design and organization, calibration for the examiner, write-up of the manuscript.

\section{Ethics approval and consent to participate}

This study was carried out with ethics board approval (HKU/HA HKW IRB: UW12-334) and parental consent forms were collected before the examinations.

\section{Consent for publication}

Not applicable.

\section{Competing interests}

The authors declare that they have no competing interests.

\section{Publisher's Note}

Springer Nature remains neutral with regard to jurisdictional claims in published maps and institutional affiliations.

\section{Author details}

${ }^{1}$ Department of Paediatric Dentistry and Orthodontics, Faculty of Dentistry, Prince Philip Dental Hospital, The University of Hong Kong, 2/F, 34 Hospital Road, Sai Ying Pun, Hong Kong SAR, China. ${ }^{2}$ Department of Orthodontics,

Tianjin Stomatological Hospital of Nankai University, 75 Dagu Road, Tianjin, China. ${ }^{3}$ Translational Research Laboratory, Faculty of Dentistry, Prince Philip Dental Hospital, The University of Hong Kong, Room 7A26, 7/F, 34 Hospital Road, Sai Ying Pun, Hong Kong SAR, China.

Received: 30 November 2017 Accepted: 13 August 2018

Published online: 22 August 2018

\section{References}

1. Peres KG, Barros AJD, Peres MA, Victoria CG. Effects of breastfeeding and sucking habits on malocclusion in a birth cohort study. Rev Saúde Pública. 2007:41(3):343-50.

2. Moimaz SA, Zina LG, Saliba NA, Saliba O. Association between breastfeeding practices and sucking habits: a cross-sectional study of children in their first year of life. J Indian Soc Pedod Prev Dent. 2008;26(3):102-6.

3. Gederi A, Coomaraswamy K, Turner PJ. Pacifiers: a review of risks vs benefits. Dental Update. 2013:40:92-101.

4. Çinar ND. The advantages and disadvantages of pacifier use. Contemp Nurse. 2004;17(1-2):109-12.

5. Adair SM. Pacifier use in children: a review of recent literature. Pediatr Dent. 2003:25(5):449-58.

6. Jackson KM, Nazar AM. Breastfeeding, the immune response, and long-term health. J Am Osteopath Assoc. 2006;106(4):203-7.

7. Exclusive breastfeeding. http://www.who.int/nutrition/topics/exclusive_ breastfeeding/en/. Accessed 29 June 2016.

8. Sum FHKMH, Zhang L, Ling HTB, Yeung CPWY, Li KY, Wong HM, Yang Y. Association of breastfeeding and three-dimensional dental arch relationships in primary dentition. BMC Oral Health. 2015;15:30.

9. Narbutytè I, Narbutytė A, Linkevičienè L. Relationship between breastfeeding, bottle-feeding and development of malocclusion. Stomatologija. 2013;15(3):67-72.

10. Rochelle IMF, Da Silva Tagliaferro EP, Pereira AC, De Castro Meneghim M, Nóbilo KA, Ambrosano GMB. Breastfeeding, deleterious oral habits and malocclusion in 5-year-old children in São Pedro, SP, Brazil. Dental Press J Orthod. 2010;15(2):71-81.

11. Xiaoxian C, Bin X, Lihong G. Effects of breast-feeding duration, bottlefeeding duration and non-nutritive sucking habits on the occlusal characteristics of primary dentition. BMC Pediatr. 2015:15:46.

12. Pires SC, Giugliani ER, Caramez Da Silva F. Influence of the duration of breastfeeding on quality of muscle function during mastication in preschoolers: a cohort study. BMC Public Health. 2012;12(1):934.

13. Turgeon-Obrien H, Lachapelle D, Gagnon PF, Maheu-Robert LF. Nutritive and non-nutritive sucking habits: a review. ASDC J Dental Child. 1996;63(5): $321-7$.

14. Jyoti S, Pavanalakshmi GP. Nutritive and non-nutritive sucking habits effect on the developing oro-facial complex: a review. Dentistry. 2014;4:203.

15. Agarwal SS, Nehra K, Sharma M, Jayan B, Poonia A, Bhattal H. Association between breastfeeding duration, non-nutritive sucking habits and dental arch dimensions in deciduous dentition: a cross-sectional study. Prog Orthod. 2014;15:59.

16. Luz CL, Carib DG, Arouca R. Association between breastfeeding duration and mandibular retrusion: a cross-sectional study of children in the mixed dentition. Am J Orthod Dentofac Orthop. 2006;130(4):531-4.

17. Solanki G, Kachhawaha B, Solanki R. Thumb sucking and pacifier use: its relationship with breastfeeding patterns. Int J Current Pharm Research. 2014:4(3):148-9.

18. Aarts C, Hörnell A, Kylberg E, Hofvander Y, Gebre-Medhin M. Breastfeeding patterns in relation to thumb sucking and pacifier use. Pediatrics. 1999; 104:e50. 
19. Canadian Paediatric Society. Recommendations for the use of pacifiers. Paediatr Child Health. 2003;8(8):515-9.

20. Sexton S, Natale R. Risks and benefits of pacifiers. Am Fam Physician. 2009; 79(8):681-5.

21. Sio JO, Minwalla FK, George RH, Booth IW. Oral candida: is dummy carriage the culprit? Arch Dis Child. 1987;62(4):406-8.

22. Comina E, Marion K, Renaud FN, Dore J, Bergeron E, Freney J. Pacifiers: a microbial reservoir. Nurs Health Sci. 2006;8(4):216-23.

23. Jabbar NS, Bueno AB, Silva PE, Scavone-Junior H, Inês Ferreira R. Bottle feeding, increased overjet and class 2 primary canine relationship: is there any association? Braz Oral Res. 2011;25(4):331-7.

24. Landis JR, Koch GC. The measurement of observer agreement for categorical data. Biometrics. 1977;33(1):159-74

25. Rosner B. Fundamentals of biostatistics. 7th ed. Belmont: Duxbury Press; 2011. p. 568-71

26. Moimaz SA, Saliba O, Lolli LF, Garbin CA, Garbin AJ, Saliba NA. A longitudinal study of the association between breast-feeding and harmful oral habits. Pediatr Dent. 2012;34(2):117-21.

27. Carrascoza KC, Possobon RF, Tomita LM, Moraes AB. Consequences of bottle-feeding to the oral facial development of initially breastfed children. J Pediatr. 2006;82(5):395-7.

28. Zadik D, Stern N, Litner M. Thumb- and pacifier-sucking habits. Am J Orthod. 1977;71(2):197-201.

29. Murray JJ, Nunn JH, Steele JG. The Prevention of Oral Disease. 4th ed. New York: Oxford; 2003. p. 158.

30. Bowden BD. The effect of digital and dummy sucking on arch widths, overbite, and overjet: a longitudinal study. Aus Dent J. 1966;11(6):396-404.

31. Warren JJ, Bishara SE. Duration of nutritive and non-nutritive sucking behaviours and their effects on the dental arches in the primary dentition. Am J Orthod and Dentofacial Orthop. 2002;121(4):347-56.

32. Ozawa N, Hamada S, Takekoshi F, Shinji H. A study on non-nutritive sucking habits in young Japanese - relationships among incidence, duration, malocclusion and nursing behavior. Pediatr Dent J. 2005;15(1):64-71.

33. Al-Dawoody AD. Finger sucking: prevalence, contributing factors and effect on occlusion. Al-Rafidain Dent J. 2004;4(2):135-42.

34. Duncan K, McNamara C, Ireland AJ, Sandy JR. Sucking habits in childhood and effects on the primary dentition: findings of the Avon longitudinal study of pregnancy and childhood. Int J Paediatr Dent. 2008;18(3):178-88.

35. Fukata O, Braham RL, Yokoi K, Kurosu K. Damage to the primary dentition resulting from thumb and finger (digit) sucking. ASDC J Dent Child. 1996; 63(6):403-7.

36. Bisharra SE, Larsson E. Finger habits: their effects and their treatments - part 2. Dent Assist. 2007;76(2):16-22.

37. Proffit WR. The orthodontic problem - the development of orthodontic problems. In: Proffit WR, Fields HW, Sarver DM, editors. Contemporary Orthodontics. Philadelphia: Mosby; 2007. p. 3-23. 130-161.

38. Kato M, Watanabe K, Kato E, Hotta H, Daito M. Three dimensional measurement of the palate using the semiconductor laser: on the influences of the palate of maxillary protrusion with finger sucking. Ped Dent J. 2009:19(1):25-9.

39. Subtelny JD, Subtelny JD. Oral habits - studies in form, function and therapy. Angle Orthod. 1973;43(4):347-83.

40. Warren JJ, Bishara SE, Steinbock KL, Yonezu T, Nowak AJ. Effects of oral habits' duration on dental characteristics in the primary dentition. J Am Dent Assoc. 2001;132(12):1685-93. 1726

41. Aznar T, Galan AF, Marin I, Dominguez A. Dental arch diameters and relationships to oral habits. Angle Orthod. 2006;76(3):441-5.

42. Ngan P, Fields HW. Openbite: a review of etiology and management. Pediatr Dent. 1997:19:91-8

43. Larsson E. Artificial sucking habits: etiology, prevalence and effect on occlusion. Int J Orofacial Myology. 1994:20:10-21.

44. Mitchell L. The aetiology and classification of malocclusion. An introduction to orthodontics. 3. New York: Oxford University Press; 2007. p. 9-10,

45. Bhat SS, Rao HT, Hegde KS, Kumar BS. Characteristics of primary dentition occlusion in preschool children: an epidemiological study. Int J Clin Pediatr Dent. 2012:5(2):93-7.

\section{Ready to submit your research? Choose BMC and benefit from:}

- fast, convenient online submission

- thorough peer review by experienced researchers in your field

- rapid publication on acceptance

- support for research data, including large and complex data types

- gold Open Access which fosters wider collaboration and increased citations

- maximum visibility for your research: over $100 \mathrm{M}$ website views per year

At BMC, research is always in progress.

Learn more biomedcentral.com/submissions 